\title{
O PROCESSO DE FORMAÇÃO DE PROFESSORES EGRESSOS DE INSTITUIÇÕES DO NORTE DO PARANÁ EM RELAÇÃO À TEORIA DO PROCESSAMENTO DA INFORMAÇÃO E SUAS IMPLICAÇÕES EDUCACIONAIS
}

\author{
Paula Mariza Zedu ALLIPRANDINI ${ }^{1}$ \\ Maria Aparecida Farias SILVA ${ }^{2}$
}

RESUMO: Este estudo adotou como metodologia uma pesquisa documental e de campo. Inicialmente, foi solicitado às Universidades e Faculdades Públicas e Privadas que oferecem o Curso de Pedagogia no norte do Paraná, os programas das disciplinas na área de Psicologia, com o objetivo de verificar, nas respectivas ementas, conteúdo programático e bibliografia se as disciplinas ofertadas na área de Psicologia da Educação trabalhavam o conteúdo da Teoria do Processamento da Informação. Na sequência, foram entrevistadas 12 professoras das séries iniciais de Escolas Municipais, egressas do curso de Pedagogia ou Normal Superior das Instituições pesquisadas, com o objetivo de verificar se essas profissionais, tendo na sua formação o conteúdo referente à Teoria do Processamento da Informação, têm aplicado este conhecimento nas suas práticas pedagógicas. A análise dos resultados apontou que o conteúdo da Teoria do Processamento é ofertado pela maioria dos Cursos de Pedagogia pesquisados, porém não tem sido utilizado de forma consciente pelos professores que tiveram acesso a esse conteúdo. Sugere-se que haja uma readequação da oferta das disciplinas na área de Psicologia da Educação relacionada a ampliação da carga horária e procedimentos metodológicos, de forma a propiciar reflexões sobre a prática pedagógica, que incluam a Teoria do Processamento da Informação como possibilidade de contribuição no processo ensino-aprendizagem

PALAVRAS-CHAVE: Formação de professores. Teoria do processamento da informação. Prática pedagógica.

Introdução

A relação da Psicologia com a educação, no decorrer de sua história, tem demonstrado duas direções distintas. Uma delas, vista como um campo científico, no qual soluções podem ser encontradas pelos educadores para seus fazeres e outra direção é a defesa daqueles que compreendem os fenômenos escolares em sua especificidade e abrangência e, por isso, passaram a legitimar a necessidade de um campo de conhecimento psicológico-científico próprio, a Psicologia da Educação (PULLIN, 2010).

De acordo com Guerra (1999 apud AZZI; BATISTA; PEREIRA, 2000, p.172),

\footnotetext{
${ }^{1}$ UEL - Universidade Estadual de Londrina - Departamento de Educação. Londrina - PR - Brasil. 86051990 - paulaalliprandini@uel.br

${ }^{2}$ Graduada em Pedagogia - UEL - Universidade Estadual de Londrina. Londrina - PR - Brasil. 86051 mf.silva1974@bol.com.br
} 
A relação entre a Psicologia e a Educação percorre dois caminhos quando é discutida no seio da formação de professores: em primeiro lugar quando se discute a sua contribuição como área de conhecimento e, em segundo lugar com a forma como aparece nos cursos através da grade curricular. Assim sendo, para melhor instrumentalizar a prática docente, o ensino de psicologia precisa considerar a possibilidade de articulação com os conhecimentos científicos e a inter-relação com as demais áreas do conhecimento no processo de formação.

Ao considerar a formação dos professores nos cursos de Pedagogia nas Instituições de Ensino Superior, deve-se pensar como os conteúdos estão distribuídos, assim como a carga horária das disciplinas, considerados aspectos importantes que podem estar refletindo na prática do docente após sua formação. Pullin (2010) realizou um estudo, a partir do documento oficial que regula a oferta do Curso de Pedagogia em uma Instituição de Ensino Superior no Brasil, que apresenta alguns dos efeitos decorrentes de condições determinadas por esse documento referente à oferta das disciplinas Psicologia da Aprendizagem e do Desenvolvimento. A autora aponta que:

\begin{abstract}
A análise do inscrito em resoluções que determinam a oferta de um curso pode auxiliar a identificar o espaço, o tempo e a natureza das atividades acadêmicas que compõem a matriz curricular desse curso, bem como o ementário das disciplinas, que integram essa matriz, informam qual o conjunto de saberes necessários para a formação profissional, legitimados por um dado corpo docente e pelas instâncias que os reafirmam. (PULLIN, 2010, p. 79).
\end{abstract}

Como a Psicologia da Educação representa um suporte para o campo educacional, é imprescindível que os cursos de formação de professores ofereçam o conhecimento das diferentes teorias, priorizando os fundamentos que melhor instrumentalizem a prática docente, conforme orienta Guerra (2000), oportunizando aos estudantes a compreensão crítica da prática educativa.

Para que os professores consigam relacionar as teorias na prática em sala de aula, acredita-se que os formadores de Psicologia da Educação devem convencer seus pares da importância dessa área de conhecimento para a formação dos futuros profissionais (LAROCCA, 2000). Além disso, os professores de Psicologia da Educação, ao refletirem sobre seus programas, poderão reestruturá-los. O importante é que os alunos sejam levados a assumirem posições perante o tema e busquem respostas/sínteses nos referenciais da Psicologia e da realidade concreta para intervenção. Propõe que se desenvolvam atividades por meio de perguntas/indagações, 
cujo pano de fundo, ao qual o professor sempre remeteria, seria composto pela seguinte tríade: o aluno que o professor tem diante de si; a realidade educacional, escolar e social; as diferentes contribuições da Psicologia (LAROCCA, 1999).

A Psicologia Cognitiva, considerada uma das teorias atuais que vem pesquisando e teorizando os processos de aprendizagem, conforme apontado por Pfromm Netto (1987), é vista como uma psicologia revolucionária, uma vez que retoma o estudo dos processos cognitivos em contraposição ao modelo proposto pelo comportamentalismo. Esta teoria atribui importância central às características de aquisição de conhecimento e processamento da informação. Os aspectos cognitivos também são destacados por Schultz e Schultz (1992), que afirmam que essa concepção da mente humana, baseada no processamento da informação, fundamenta a psicologia cognitiva.

Este modelo teórico partiu de estudos realizados com a finalidade de conhecer como o aprendiz processa a informação, os quais levaram vários pesquisadores a elaborarem a metáfora do processamento da informação, em que a aprendizagem e o raciocínio humano ocorrem de modo semelhante ao processamento do computador. Como nos computadores, que incluem o fluxo da informação com entrada, processamento e resultado impresso na tela (BZUNECK, 2004). Embora existam críticas a esse modelo de processamento da informação, a metáfora auxilia na compreensão de como o aprendiz constrói e armazena um novo conhecimento e tem levado ao desenvolvimento de estudos em torno de estratégias de aprendizagem (BZUNECK, 2004).

Dembo (1994 apud BORUCHOVITCH, 1999) aponta que o propósito do uso das estratégias de aprendizagem é ajudar o aluno a controlar o processamento da informação, de modo que ele possa melhor armazenar e recuperar a informação da memória de longa duração.

Vários autores (BROWN, 1997; CLARK, 1990; PRESSLEY; LEVIN, 1983, apud BORUCHOVITCH, 1999) defendem que pesquisas têm evidenciado que é possível ajudar os alunos a exercer maior controle e refletir sobre seu próprio processo de aprendizagem por meio do ensino de estratégias de aprendizagem.

Com base no princípio de que a criança é um sujeito com potencialidades para aprender, o educador precisa receber formação adequada para desenvolver com sucesso seu trabalho. O conhecimento da Teoria do Processamento da Informação pode ajudar o educador a desenvolver de modo satisfatório a aprendizagem do aluno. 
O ensino de estratégias de aprendizagem favorece o rendimento escolar do aprendiz, pode produzir a melhoria imediata tanto no uso de estratégias envolvidas como no rendimento escolar geral (GOMES; BORUCHOVITCH, 2005; COSTA, 2000).

Costa (2000) apresenta três tipos de pesquisas: aquelas que têm associado às estratégias de aprendizagem as variáveis psicológicas, demográficas e culturais que afetam o seu uso; aquelas que têm procurado avaliar os efeitos de programas de treinamento em estratégias de aprendizagem no desempenho escolar e aquelas voltadas para melhoria da formação de professores, que tem procurado contribuir para a formação dos futuros professores bem como para sua prática através do esclarecimento, da informação e do treinamento de tais profissionais sobre a importância das estratégias de aprendizagem, metacognição e das variáveis afetivas para um ensino e uma aprendizagem eficiente, assim como para o sucesso acadêmico dos estudantes.

Costa e Burochovitch (2009) destacam que a intervenção com estratégias de aprendizagem possibilitou produção de textos com melhor qualidade, identificados por uma estrutura narrativa adequada, melhores articulações de ideias, menos erros ortográficos e maior número de linhas.

Flavell (apud CHAHON, 2006) sustenta que as habilidades metacognitivas infantis, envolvendo a capacidade de monitorar - saber localizar-se em relação à sua meta - e autorregular-se - planejar e avaliar - seu comportamento, desenvolvem-se desde os sete anos e podem ser ensinadas dentro do currículo escolar.

Entre os fatores responsáveis pelo fracasso escolar, a motivação do aluno tem sido apontada como ausência do envolvimento do aprendiz em seus estudos. A motivação está relacionada ao desempenho escolar do aprendiz, apesar de poucos dados empíricos confirmarem essas relações. Diante das investigações já realizadas, as mesmas indicam que a motivação intrínseca e as ações do professor em sala de aula são relevantes na promoção de aprendizagem do aluno (MARTINELLI; GENARI, 2009).

Bzuneck (2010) descreve as principais estratégias com potencial de levar os alunos a valorizarem o aprender. Uma estratégia motivacional consiste em aproveitar interesses pessoais e valores dos próprios alunos. Mostrar o valor instrumental da atividade é uma estratégia motivacional, outra, é o professor que deve ser modelo para seus alunos ao demonstrar que acredita na importância da disciplina.

Segundo Onrubia e Woolfolk (apud BZUNECK. 2010), ajudas e apoios a serem prestados pelo professor ou colega incluem ações que vão desde organização de horário, 
escolha de espaço físico e de maneiras até o fornecimento de pistas, de modelo, regulação da dificuldade, recuperação ou reposição de conhecimentos prévios relevantes, fornecimento de exemplos semiprontos e, por fim, feedeback a cada passo dado.

Bzuneck (2010) assevera que, para o aluno construir conhecimentos, precisa envolver-se e engajar-se nas atividades. Inclui prestar atenção em classe, tomando notas, até a redação de trabalhos e preparação para provas. Para tal envolvimento, precisa ver significado e a importância das aprendizagens; sentir-se desafiado; ter o professor como modelo de entusiasmo e apreço para os estudos; sentir emoções positivas; perceber que suas realizações são reconhecidas e que seus pequenos fracassos podem ser superados. Motivar alunos, portanto, é questão de estratégias variadas, a serem usadas combinadamente e, ao mesmo tempo, de forma discriminada conforme as circunstâncias.

Wintter (2010) aponta que a figura-chave na escola para motivar os alunos para a leitura é o professor, com conhecimento sobre motivação e estratégias motivadoras no ensino de leituras e outras tecnologias.

Os educadores podem auxiliar o sucesso na escrita e facilitar o processamento da informação com divisão de tarefas complexas em partes manejáveis, auxiliando o monitoramento do progresso durante o processo da escrita (COSTA; BORUCHOVITCH, 2010). Mostrar a relevância da tarefa para o aluno, além de conferir importância, aumenta a probabilidade de que a motivação intrínseca do aluno alcance um nível maior (COSTA; BORUCHOVITCH, 2010).

Ao consideram a relevância da contribuição da Psicologia Cognitiva no processo de escolarização do aluno, conhecer sobre o processo de formação de professores das Séries Iniciais do Ensino Fundamental sobre o conhecimento desta perspectiva teórica e sua contribuição na realização do trabalho pedagógico junto aos alunos poderá contribuir para que os cursos de formação de professores possam rever a oferta de disciplinas na área de Psicologia da Educação, de forma que contemple em suas ementas o conteúdo da Psicologia Cognitiva, em especial da Teoria do Processamento da Informação e também para uma reflexão sobre a aplicação de seus conteúdos nas suas práticas pedagógicas no contexto escolar.

Para este estudo, adotou-se como metodologia uma pesquisa documental e de campo. Inicialmente, foi solicitado às Universidades e Faculdades Públicas e Privadas que oferecem Curso de Pedagogia no município de Londrina/PR os programas das 
disciplinas na área de Psicologia, com o objetivo de verificar, nas respectivas ementas, conteúdo programático e bibliografia, se as disciplinas ofertadas na área de Psicologia da Educação trabalhavam o conteúdo da Teoria Cognitivista, em especial da Teoria do Processamento da Informação.

Após a obtenção desse material, foram entrevistadas 12 professoras das séries iniciais de Escolas Municipais de Londrina, PR formadas em Pedagogia ou Normal Superior, egressas das Instituições pesquisadas, com o objetivo de verificar se essas profissionais, tendo recebido na sua formação o conteúdo referente à Psicologia Cognitiva, têm aplicado esta Teoria em suas práticas pedagógicas.

\section{Procedimentos metodológicos}

Inicialmente, foi solicitado às Universidades e Faculdades Públicas e Privadas que oferecem o Curso de Pedagogia na região norte do Paraná, os programas das disciplinas na área de Psicologia, com o objetivo de verificar, nas respectivas ementas, conteúdo programático e bibliografia, se a disciplina trabalha o conteúdo da Teoria Cognitivista, em especial da Teoria do Processamento da Informação. O programa das disciplinas foi solicitado junto à coordenação dos cursos de pedagogia ofertados ou a alunos matriculados nestes cursos. Os recursos utilizados para a obtenção deste material foram a Internet (e-mail ou site), contato telefônico ou visitas às faculdades quando necessário.

Após a obtenção do material, foi solicitado à Secretaria de Educação autorização para visitar as escolas e realizar entrevistas com os professores que se dispuseram a responder as questões, tendo sido adotado todos os procedimentos éticos. Foram entrevistadas 12 professoras das séries iniciais de cinco Escolas Municipais de Londrina, sendo que nove entrevistadas (75\%), têm trabalhado com as séries iniciais e educação infantil. O restante das participantes (25\%) tem experiência apenas nas séries iniciais. Quanto ao tempo de magistério, este varia de um a 31 anos de experiência, sendo que apenas 1 entrevistada tem 1 ano; 2, três anos; 2. cinco anos; 1 , seis anos; 2, 15 anos; 2, vinte anos; 1, 22 anos e 1, trinta e um anos de experiência. Metade das participantes possuem especialização.

Utilizou-se um roteiro para as entrevistas com questões pertinentes à investigação, as quais foram gravadas e posteriormente transcritas. Vale ressaltar que 
uma das Instituições pesquisadas não teve nenhum professor entrevistado, considerando que, no momento da realização das entrevistas ainda não tinha alunos egressos.

\section{Resultados e discussões}

\section{Análise dos programas das disciplinas da área de psicologia da educação}

No processo de análise dos programas das Instituições nominadas como A, B, C,

D e E, foram observados a ementa das disciplinas ofertadas, o conteúdo programático e a bibliografia, com o objetivo de verificar se o conteúdo sobre a Psicologia Cognitiva, em especial a Teoria do Processamento da Informação, foi trabalhado com os alunos no seu processo de formação.

Após a análise, foi verificado que a Instituição A oferece a disciplina Psicologia da Aprendizagem A, com carga horária de 68 horas. A sua ementa contempla a Teoria do Processamento da Informação e, em seu conteúdo programático, a disciplina destaca o papel do professor e as atividades mentais do aluno e, ainda como temas atuais em aprendizagem, o conteúdo sobre motivação e estratégias de aprendizagem sob a mesma perspectiva teórica.

A mesma análise referente à Instituição B possibilitou verificar que a mesma apresenta na sua grade curricular a oferta da disciplina Desenvolvimento Humano e Aprendizagem: Jovens e Adultos, com um total de 40 horas. A sua ementa contempla as teorias da aprendizagem do jovem e do adulto e tem como objetivos caracterizar e analisar as principais abordagens teóricas que fundamentam o processo de aprendizagem e refletir acerca das crenças pessoais sobre a aprendizagem de jovens e adultos, inteligência, desenvolvimento e motivação. Na sua unidade III, que discorre sobre as Teorias de Aprendizagem e suas implicações no processo de ensino e aprendizagem de jovens e adultos, uma das teorias propostas é a cognitivista. Apresenta na sua bibliografia os autores: Evely Boruchovith e José Aloyseo Bzuneck.

Foi verificado que a Instituição C oferece a disciplina Psicologia do Desenvolvimento e Aprendizagem, com carga horária de 70 horas. Esta disciplina propõe na ementa o estudo do desenvolvimento e da aprendizagem orientado por diferentes referenciais, uma vez que sua ementa aborda sobre o desenvolvimento humano e aprendizagem: conceitos, teorias e implicações nos processos de ensino. Propõe, na unidade IV, a aprendizagem na perspectiva de diferentes teorias. Ao 
verificar as referências bibliográficas apresentadas no programa da disciplina, as mesmas não se reportam ao conteúdo da Teoria do Processamento da Informação.

Na Instituição D, foram analisadas as disciplinas seguintes: Abordagens Psicológicas da Aprendizagem I, com 60 horas e Abordagens Psicológicas da Aprendizagem II, com 80 horas. A análise permitiu verificar que a proposta da Teoria do Processamento da Informação não foi trabalhada nas duas disciplinas, já que não constam nas respectivas ementas, programas e bibliografias indicações de que esta teoria tenha sido trabalhada pela disciplina.

A Instituição E oferta a disciplina de Psicologia do Ensino e Aprendizagem junto ao Curso de Pedagogia, com carga horária de 80 horas. A bibliografia básica privilegia sobre o desenvolvimento e o cognitivismo na sala de aula por meio dos autores Coll e colaboradores. Na bibliografia complementar, propõe textos de Moreira, Bock e Hadji, E. Na sua ementa, discorre sobre o estudo do desenvolvimento e da aprendizagem mediante a relação dos princípios subjacentes ao processo de ensino, psicologia da aprendizagem e de ensino e o processo de construção do conhecimento. Em seu programa, aborda sobre a aprendizagem por processamento da informação: uma visão construtivista com o objetivo de entender como ocorre a aprendizagem na mente de um aprendiz. Ainda com base na teoria cognitivista, apresenta em seu conteúdo a motivação do aluno e sua relação com a aprendizagem, destacando a compreensão da importância da motivação acadêmica no processo de aprendizagem e utilizando as obras dos autores Evely Boruchovith e José Aloyseo Bzuneck.

Portanto, considerando todas as Instituições pesquisadas, a maioria apresenta na sua ementa, conteúdo programático e bibliografia a Teoria Cognitivista/Processamento da Informação, sendo que as Instituições C e D são as únicas que não contemplam este referencial teórico.

\section{Análise das entrevistas com as professoras}

A primeira questão procurou saber a respeito dos conteúdos da área de Psicologia que cada participante teve no curso de formação em Pedagogia e/ou Normal Superior. Os conteúdos que se destacaram, na Instituição A, foram sobre as fases do desenvolvimento, Skinner e Freud, construtivismo e relação professor-aluno. As disciplinas psicologia do desenvolvimento, psicologia I e II e também psicologia social foram citadas. As participantes egressas da Instituição B se reportam a Piaget e 
Vigostky, desenvolvimento infantil, fases do desenvolvimento, mediação, desenvolvimento proximal e estimulação/socialização. As respostas das professoras egressas da Instituição $\mathbf{C}$ se remeteram à psicologia do desenvolvimento, desenvolvimento cognitivo, psicologia infantil, psicologia do aprendizado e desenvolvimento do aluno. As egressas da Instituição E apontaram sobre desenvolvimento da criança, desenvolvimento intelectual, Piaget e Vigostky, interação do meio e estímulo, fases do desenvolvimento, comportamento e doenças psicológicas. Uma das entrevistadas se referiu à disciplina Psicologia da Educação, de forma geral, sem especificar os conteúdos. Em relação às respostas apresentadas pelas entrevistadas, vale ressaltar que nenhum dos professores egressos das diferentes Instituições mencionou a Teoria do Processamento da Informação como uma das teorias trabalhadas.

Ao responder a segunda questão, a qual investigou sobre o conhecimento adquirido em relação ao cognitivismo e à teoria do processamento da informação, as participantes da pesquisa egressas da Instituição A fizeram relação com o desenvolvimento intelectual, estágios de Piaget, mediação, conhecimentos prévios e como o conhecimento se processa para ser construído. Uma das participantes não respondeu a esta questão. As respostas das participantes formadas pela Instituição B descreveram sobre a capacidade de guardar conhecimento, construção do conhecimento na criança, desenvolvimento segundo Piaget e Vigostky e que quanto mais estímulo é dado, mais se aprende. As participantes formadas pela Instituição C, em relação à segunda questão, deram como resposta à construção do conhecimento, as fases do desenvolvimento, desenvolvimento intelectual, sendo que uma delas afirmou ter tido este conteúdo, porém não conseguiu lembrar de que se trata. A primeira entrevistada da Instituição $\mathbf{E}$ respondeu não se lembrar, outra participante fez referência à importância da mediação do professor, partir dos conhecimentos prévios dos alunos, trabalhar de acordo com a zona de desenvolvimento proximal, citou as fases da alfabetização de Emília Ferreiro. A terceira participante se referiu a como se dá a aprendizagem da criança. No geral, ao investigar sobre o conhecimento, o Cognitivismo/Teoria do Processamento da Informação, há poucas evidências deste conhecimento por parte das pesquisadas, sendo que egressas das Instituições A e B descreveram como o conhecimento se processa para ser construído, sobre a capacidade de guardar o conhecimento e a construção do conhecimento. 
Em relação à identificação de alunos com dificuldades de aprendizagem, conforme abordado pela questão três, os relatos das participantes formadas pela Instituição A foram: não há progresso quando comparado o desempenho em relação a ele mesmo, que as identifica pelas atividades desenvolvidas, ritmos diferentes, sondagem e comportamentos. As egressas da Instituição B responderam que reconhecem pelas avaliações diagnósticas, também pelo desenvolvimento das atividades e comportamentos. As egressas da Instituição C descreveram que as crianças não acompanham de acordo com pré-requisitos, comportamento, modo de pensar, fala, perguntas e resultados de atividades. Uma das entrevistadas ainda informa que o diagnóstico sobre as dificuldades de aprendizagem é realizado por um profissional especializado. Finalmente, as egressas da Instituição E relataram que as crianças com dificuldades de aprendizagem não acompanham a turma, pelo diagnóstico, apresentam dificuldade em realizar as atividades, passam por avaliação da psicopedagoga para identificar a dificuldade, por meio de observação diária, questionamento para identificar a dificuldade, avaliações individuais mensais, arquivos e portfólios. A análise destas respostas permitiu verificar, em relação à contribuição da Teoria do Processamento da Informação, algumas indicações do conhecimento sobre a teoria, como, por exemplo: a falta de concentração em que a criança não colhe a informação, dificuldades em resolver cálculos matemáticos, decodificação de texto e também o modo de pensar.

A quarta questão investigou sobre a forma que as participantes trabalham com os alunos que apresentam dificuldades. As formadas pela Instituição A afirmaram que utilizam outros recursos para trabalhar o conteúdo, atendimento individual, família, apoio da escola, trabalham o concreto, jogos, dinâmicas e auxiliar para reforço. As professoras da Instituição B responderam que trabalham as dificuldades por meio de atendimento individual, apoio de outras pessoas (profissionais, família), identificação da dificuldade, estímulos, jogos, autoestima e concentração. As respostas das egressas da Instituição $\mathbf{C}$ apontaram que retomam a atividade, por meio de trabalho individual, jogos pedagógicos, material diferenciado, atividade rodada extra (contraturno), trabalho em grupos (trocas de integrantes) e motivação. As egressas da Instituição E declararam em suas respostas que fazem o resgate de atividades em que a criança apresentou dificuldade, desenvolvem atividades específicas como atividades com mediação, jogos (lúdico), atendimento individual, atividades diferenciadas (sala de aula), aula de apoio (contraturno) e identificação da dificuldade. Ao analisar as respostas apresentadas pelas professoras em relação ao processo de intervenção frente às dificuldades de 
aprendizagem, algumas delas parecem se reportar à Teoria do Processamento da Informação quando apontam sobre a concentração, motivação e resgate da atividade em que 0 aluno apresentou dificuldades.

A questão cinco pretendeu conhecer sobre o trabalho desenvolvido com os alunos nas atividades de leitura e compreensão de textos. As participantes egressas da Instituição A afirmaram desenvolver as atividades de leitura e compreensão de textos mediante a utilização de música, parlendas, textos diversificados, leitura silenciosa, leitura coletiva e em grupo, ler as partes para perceber o que não conseguiram ler. As respostas das professoras formadas pela Instituição B informaram que desenvolvem estas atividades por meio de discussões sobre o texto, debates, utilizando diversos impressos, mural de notícias, músicas, contação de histórias, e incentivam a leitura por meio do registro, desenho/escrita, leitura realizada com a família, oralidade, questionamentos orais, leitura em grupo e continuada e atividades de grifar partes importantes dos textos. As participantes egressas da Instituição C se referiram ao uso da leitura de jornais e textos que tratam da realidade, músicas, histórias conhecidas, discriminação de letras, leitura silenciosa e em voz alta, questionamentos orais, debates sobre temas, troca de informações, pesquisa em dicionário, texto do livro, a partir de um brinquedo, brincadeiras, curiosidades, assunto trazido pelos alunos, estabelecendo relação com o contexto da criança. As participantes egressas da Instituição E descreveram sobre o desenvolvimento de atividades como a hora da leitura, leitura em casa, registro por meio de desenho/texto, leitura no microfone, uso de texto curto, mensagem no quadro, textos diversos (Projeto Sacola de Leitura), leitura com a família, caderno de registro de leitura, leitura individual, leitura em grupo, leitura continuada, discussão em grupo, questionário, organizar textos na sequência, assim como o uso de estímulos e elogios. Ao analisar as repostas das entrevistadas, algumas parecem se remeter mais aos recursos, relacionando, em alguns aspectos, o uso de algumas estratégias relacionadas à Teoria do Processamento da Informação, como o uso de questionários, organização de textos na sequência, registro por meio de desenho/texto.

A última questão visou conhecer sobre o uso de alguma estratégia para tornar a aprendizagem significativa. As respostas das egressas da Instituição A relataram que utilizam gibis, livros, material concreto, jogos, relacionam o conteúdo com o contexto do aluno, buscam conhecer a realidade do aluno, brinquedos, brincadeiras, fantoches e estímulo. As professoras egressas da Instiuição B responderam que utilizam: jogos, revistas, palavras cruzadas, caça-palavras, sudoku, brincadeiras, material concreto e 
procuram identificar o interesse dos alunos. As respostas das participantes egressas da instituição $\mathbf{C}$ afirmaram que trabalham sempre o que tem significado para o aluno e com o uso de jogos, recursos audiovisuais, músicas (interpretação de textos, microfone) e retroprojetor. As egressas da Instituição $\mathbf{E}$ responderam que se valem do incentivo/elogios, recursos audiovisuais, sondagem dos conhecimentos prévios, fantoche, datashow, brincadeiras, dinâmicas, relacionam conteúdos com filmes, e utilizam também gibis, revistas, computador e notícias atuais. As respostas apresentadas pelas pesquisadas sobre as estratégias utilizadas para tornar a aprendizagem significativa estão relacionadas ao interesse/motivação do aluno, ao contexto da aluno, à preocupação com conhecimentos prévios. Algumas das participantes se reportam mais aos recursos materiais e às brincadeiras utilizadas.

\section{Relação entre o processo de formação e a prática pedagógica}

Esta análise busca relacionar o processo de formação e o uso do referencial teórico da Psicologia Cognitiva, em especial da Teoria do Processamento da Informação, na prática pedagógica das professoras entrevistadas.

De forma geral, os resultados apontaram que as Instituições A, B e E contemplam em seus Programas as disciplinas de Psicologia, Teoria do Processamento da Informação, abordando a proposta cognitivista, pois uma vez que constam, nos seus respectivos conteúdos programáticos e/ou em suas referências bibliográficas, obras que contemplam a proposta da Teoria do Processamento da Informação.

As professoras egressas das Instituições que ofertam o conteúdo do tema pesquisado, nas respostas da segunda questão, apontam como o conhecimento se processa, fazem referência à retenção de conhecimento, à construção do conhecimento e como a criança aprende (desenvolvimento intelectual) e podem estar relacionando-os com a Teoria do Processamento da Informação. Todavia, as professoras entrevistadas não abordaram diretamente os conteúdos da Teoria do Processamento da Informação. Ao analisar as respostas das egressas da Instituição C, Universidade em que não se encontrou indicativo sobre a abordagem da Teoria do Processamento da Informação nas análises dos programas, ementas e bibliografia, uma das respostas das entrevistadas descreve sobre a construção do conhecimento e grande parte das entrevistadas aponta a Teoria de Piaget, o que indica a importância de algumas teorias da área de Psicologia da Educação na formação dos professores. 
Concordando com Guerra (2000), é necessário que os cursos de formação de professores estejam priorizando os fundamentos que melhor instrumentalizem a prática docente. No entanto, por algum motivo, a forma como está sendo trabalhada no processo de formação, a Teoria do Processamento da Informação não corresponde à contribuição que a mesma tem a oferecer, uma vez que a mesma não vem sendo utilizada no contexto de sala de aula.

Observou-se, nas respostas referentes à questão quatro, que a professora 1, egressa da Instituição C, cita a motivação para trabalhar com o aluno com dificuldade de aprendizagem, considerado um tema discutido pela Teoria Cognitivista. Vale ressaltar que esta professora cursou uma pós-graduação e talvez este tema tenha sido trabalhado neste nível de formação.

A presente pesquisa vem confirmar a importância das diversas teorias da Psicologia na prática do trabalho pedagógico em sala de aula, evidenciando que as professoras recorrem a elas frequentemente para superar as dificuldades de aprendizagens dos alunos. Demonstraram, de acordo com suas respostas, estarem atentas às concepções teóricas ofertadas pela Psicologia da Educação, como, por exemplo, as de Piaget, Skinner, Vygotsky e Freud, que fundamentam a prática dos professores. Porém nem todo o conteúdo trabalhado durante o processo de formação profissional permaneceu para uso consciente na prática, uma vez que as profissionais que tiveram, durante a graduação, o conteúdo da Teoria do Processamento da Informação não apresentaram os termos desse modelo teórico, ou seja, não fizeram referência às temáticas como estratégias de aprendizagens, cognição e metacognição, memória, dentre outras.

Ao desenvolver as atividades pedagógicas, as profissionais investigadas se valem de algumas estratégias de aprendizagem, como as de ensaio (fala e escrita), organização, com o exemplo de organização de um texto, as estratégias de elaboração de conexões entre o material que se conhece e o material que deseja a aprender. Destaca-se a motivação, como uma das estratégias afetivas, que, segundo (MARTINELLI; GENARI, 2009), está entre os fatores responsáveis pelo sucesso do desempenho escolar do estudante e assinalam que a motivação intrínseca e as ações do professor em sala de aula são relevantes na aprendizagem do aluno. Bzuneck (2010) se refere à estratégia motivacional, que consiste em aproveitar os interesses pessoais e valores dos próprios alunos. Outra estratégia motivacional é o professor ser modelo ao demonstrar que acredita na importância da disciplina. As respostas de algumas egressas 
das Instituições pesquisadas fazem referência à contextualização no uso de assunto, ser exemplo para incentivar a leitura, curiosidade, brincadeiras/brinquedos, as vivências fora da escola que estão relacionadas à vida do aluno e também com os acontecimentos da atualidade.

Em relação à atividade de leitura, o uso de tecnologia (por exemplo, microfone) para leitura de textos, mencionado por algumas das entrevistadas, pode ser relacionado às estratégias motivadoras apresentadas por Witter (2010) sobre motivação e estratégias motivadoras para o ensino de leitura. Os conhecimentos prévios do aluno se apresentam nas respostas que enfatizam o uso de recursos/tecnologia para auxiliar a aprendizagem, a realização de atividades em grupo, oferecendo atividades que os alunos tenham condições de realizar, são aspectos que podem estar relacionadas às estratégias afetivas que se traduzem em atenção, concentração e manutenção da motivação. Observou-se o uso de estratégias variadas para atividades de leitura e compreensão de textos por meio de pesquisa em dicionário, na qual se supõe o reconhecimento, por parte do aluno, de palavras do texto que não teve compreensão, sublinhar palavras, registro da leitura, questionamentos orais, organizar, sequencialmente, partes de um texto; leitura coletiva, que possibilita perceber a dificuldade; acompanhar leitura individual com feedback do professor. Portanto, as entrevistadas apontam para estratégias que se remetem a estratégias cognitivas e metacognitivas.

Os recursos utilizados pelas professoras na prática pedagógica para favorecer a aprendizagem refletem o uso de estratégias baseadas na Teoria do Processamento da Informação embora, em seus processos de formação, as pesquisadas não tenham feito referência a esta teoria ao responderem a primeira questão deste estudo. Ao analisar a formação de professores nos Cursos de Pedagogia, deve-se observar a carga horária, a distribuição dos conteúdos e as atividades acadêmicas desenvolvidas para otimizar o resultado na prática. Conforme apontado por Pullin (2010) sobre a oferta das disciplinas da área de Psicologia da Educação, o ementário das disciplinas informa qual o conjunto de saberes necessários para a formação profissional. De acordo com Larocca (2000), para que os professores consigam relacionar as teorias na prática de sala de aula, é necessário convencer seus pares do valor da Psicologia da Educação na formação dos professores. A autora sugere que os professores de Psicologia da Educação, quando refletem sobre seus programas, poderão reestruturá-los direcionando os alunos, durante seu processo de formação, na busca de respostas/sínteses nos referenciais da teoria da Psicologia e da realidade concreta para intervenção. Para isto, devem estar pautados na 
proposta de conduzir o programa por meio de perguntas/indagações, cujo pano de fundo, a que os professores sempre se remeteria, seria composto pela seguinte tríade: ao aluno que o professor tem diante de si; à realidade educacional, escolar e social e às diferentes contribuições da Psicologia.

\section{Considerações finais}

Diante das análises dos programas das disciplinas ofertadas na área de Psicologia pelos Cursos de Pedagogia das Instituições pesquisadas e a relação estabelecida com as respostas das professoras formadas nas respectivas Instituições, observou-se que as professoras, mesmo não se remetendo à Teoria do Processamento da Informação, ou a termos utilizados por este referencial teórico, fazem uso da Psicologia Cognitiva em sua prática, recorrendo ao uso das estratégias de aprendizagem de modo a revelar a contribuição desta teoria para a prática pedagógica das profissionais que atuam nas Séries Iniciais. É importante que, durante a formação do professor, seja possibilitada uma reflexão sobre suas ações, que se relacionem teorias às suas práticas educativas e se possa planejar e avaliar suas ações visando a tornar mais eficiente sua atuação como educador e comprometido com seu trabalho.

Considerando a importância da Teoria do Processamento na prática pedagógica, no sentido de conhecer como o aprendiz recebe, processa e recupera a informação, sobre a importância da motivação para a aprendizagem e também sobre a contribuição das estratégias de aprendizagem para a aquisição de conhecimentos do estudante, é preciso que haja uma adequação dos Cursos de Pedagogia, neste caso, relacionada à oferta das disciplinas na área de Psicologia da Educação. Esta adequação pressupõe que se priorize em suas ementas a Teoria do Processamento da Informação, sendo necessário, para isto, um aumento da carga horária desta área de conhecimento, para que contemple este conteúdo de forma satisfatória e que permita o desenvolvimento de atividades que possibilitem discussões teórico/práticas, propiciando reflexões sobre a contribuição da Teoria do Processamento da Informação na prevenção e intervenção frente às dificuldades de aprendizagem do aluno. 


\section{THE PROCESS OF FORMER TEACHERS' DEVELOPMENT IN INSTITUTIONS FROM THE NORTH OF PARANA CONCERNING THE THEORY OF INFORMATION PROCESSING AND ITS EDUCATIONAL IMPLICATIONS}

ABSTRACT: This study was developed through a documental and field research. Initially, discipline programs in the area of Psychology were required from Public and Private Universities and Colleges in the North of Parana that offered the Pedagogy Course. The aim was to verify, in the issues related to the discipline programs, contents and bibliography, if the disciplines in the area of Education Psychology were proposing to deal with the Theory of Information Processing. To follow, 12 teachers of the initial series of Municipal Schools, which were former students of the Pedagogy (Normal Superior) Course at the institutions under scrutiny, were interviewed. The interviews aimed at verifying if these professionals, having previously studied the Theory of Information Processing during the pre-service, had been applying the knowledge in their pedagogic practices. The analysis of the results pointed that the content about the Theory of Information Processing is offered by most of the Pedagogy Courses researched, though it has not been consciously used by the teachers who had access to this content in college. Based on these results, it is understood that a rehabilitation in the offer of disciplines in the area of Education Psychology is needed, particularly regarding an increase in the workload and methodological procedures, in order to provide reflections on the teaching practice, including the Theory of Information Processing as a possibility of contribution in the teaching and learning process

KEYWORDS: Teachers development. Theory of information processing. Pedagogical practice.

\section{REFERÊNCIAS}

AZZI, R. G.; BATISTA,S. H. S. da S.; PEREIRA, M. A. L. Ensino de psicologia na licenciatura: como estratégias facilitadoras da articulação entre realidade da escola e conteúdo teórico. In: AZZI, R. G.; BATISTA, S. H. S. da S.; SADALLA, A. M. de A. (Org.). Formação de professores: discutindo o ensino de psicologia. Campinas: Alínea, 2000. p.163-180.

BORUCHOVITCH, E. Algumas estratégias de compreensão em leitura de alunos do ensino fundamental. Psicologia Escolar e Educacional, Campinas, v.5, n.1, p.19-26, jun. 2001. Disponível em: <http:/www.scielo.br/cgi-bin/wxis.exe/iah>. Acesso em: 22 jun. 2011.

Estratégias de aprendizagem e desempenho escolar: considerações para a prática educacional. Psicologia: Reflexão e Crítica, Porto Alegre, v.12, n.2, p.361-376, 1999. Disponível em: <http:/www.scielo.br/cgi-bin/wxis.exe/iah>. Acesso em: 22 mar. 2010. 
BZUNECK, J. A. Como motivar os alunos: sugestões práticas. In: BORUCHOVITCH, E.; BUZNECK, J. A.; GUIMARÃES, S. É. R. (Org.). Motivação para aprender: aplicações no contexto educativo. Petrópolis, RJ: Vozes, 2010. p.13-42.

. Aprendizagem por processamento da informação: uma visão construtivista. In: BORUCHOVITCH, E.; BZUNECK, J. A. Aprendizagem e os processos sociais na escola. Petropólis, RJ: Vozes, 2004. p.17-54.

CHAHON, M. Metacognição e resolução de problemas aritméticos verbais: teoria e implicações pedagógicas. Revista do Departamento de Psicologia, Niterói, v.18, n.2, p.163-176, jul./dez. 2006. Disponível em: <http:/dx.doi.org/101590/S0104$80232006000200012>$. Acesso em: 12 jun. 2011.

COSTA, E. R. As estratégias de aprendizagem e a ansiedade de alunos do ensino fundamental: implicações para a prática educacional. 2000. 156f. Dissertação (Mestrado em Educação) - Universidade Estadual de Campinas, Campinas, 2000.

COSTA, E. R.; BORUCHOVITCH, E. Motivação e escrita: algumas contribuições para a prática pedagógica motivacional. In: BORUCHOVITCH, E.; BUZNECK, J. A.; GUIMARÃES, S. É. R. (Org.). Motivação para aprender: aplicações no contexto educativo. Petrópolis, RJ: Vozes, 2010. p.193-208.

As estratégias de aprendizagem e a produção de textos narrativos. Psicologia:

Reflexão e Crítica, Porto Alegre, v.22, n.2, 2009. Disponível em:

<http:/dx.doi.org/101590/S0102-797222009000200001>. Acesso em: 12 jun. 2011.

GUERRA, C. T. Conhecimentos psicológicos e formação de professores. In: AZZI, R. G.; BATISTA, S. H. S. da S.; SADALLA, A. M. de A. (Org.). Formação de professores: discutindo o ensino de psicologia. Campinas: Alínea, 2000. p.67-96.

GOMES, M. A. M.; BORUCHOVICH, E. Desempenho no jogo, estratégias de aprendizagem e compreensão na leitura. Psicologia: Teoria e Pesquisa, Brasília, v.21, n.3, p.319-326, set.-dez. 2005. Disponível em: <http:/www.scielo.br/cgibin/wxis.exe/iah>. Acesso em: 22 mar. 2010.

LAROCCA, P. Conhecimentos psicológicos e formação de professores. In: AZZI, R. G.; BATISTA, S. H. S. da S.; SADALLA, A. M. de A. (Org.). Formação de professores: discutindo o ensino de psicologia. Campinas: Alínea, 2000. p.119-145.

A psicologia na formação docente. Campinas: Alínea, 1999.

MARTINELLI, S. C.; GENARI, C. H. M. Relações entre desempenho escolar e orientações motivacionais. Estudos de Psicologia, Natal, v.14, n.1, p.13-21, jan. 2009. Disponível em: <http://www.scielo.br/pdf/epsic/v14n1/a03v14n1.pdf>. Acesso em: 10 jun. 2011.

PFROMM NETTO, S. Psicologia da aprendizagem e do ensino. São Paulo: EPU, 1987. 
PULLIN, E. M. M. P. Processo de aprendizagem e formação de professores. In: OLIVEIRA, F. N. de; ALLIPRANDINI, P. M. Z.; MELETTI, S. M. F. (Org.).

Educação em reflexão: contribuição teórica, atuação docente e pesquisa. Londrina: EDUEL, 2010. p.75-93.

SCHULTZ, D. P.; SCHULTZ, S. E. História da psicologia moderna. 11.ed. São Paulo: Cultrix, 1992.

WITTER, G. P. Motivação e leitura. In: BORUCHOVITCH, E.; BUZNECK, J. A.; GUIMARÃES, S. É. R. (Org.). Motivação para aprender: aplicações no contexto educativo. Petrópolis, RJ: Vozes, 2010. p.169-192. 